\title{
Decolonising Research Methodologies in East Arnhem Land
}

\author{
Moana Pera Tane ${ }^{1}$ \\ Menzies School of Health Research \\ moana-bella@gmail.com
}

\author{
Matire Harwood ${ }^{2}$
}

University of Auckland

m.harwood@auckland.ac.nz

Keywords: Indigenous, Aboriginal Australian, smoking, tobacco, culture, tradition, history.

\begin{abstract}
'Talking About Smoking in East Arnhem Land: Denormalisation, Stigmatisation and Leadership' was a research project that began in 2014 in East Arnhem Land, amongst the Yolnu peoples. The study revealed a wealth of deeper meanings and beliefs about narali' or tobacco within the context of Yolnu tradition, history and culture. In this reflective piece, the primary author describes a personal journey of learning through observations and discussions with Yolnu informants who shared their values, expectations and obligations associated with yarali', which over time, have become interwoven with Yolnu ceremony.
\end{abstract}

\section{Dedication}

Qualitative research was considered to be the most appropriate methodology to seek insight and understanding from Yolnu individuals, family members, leaders and employees of health services about narali' (tobacco). Yolnu informants were interviewed in clinics, on verandas, under trees outside their homes, and in the home of the researcher, who together with two Cultural Mentors (CMs) sought to create spaces where Yolnu informants were at ease, and felt comfortable to discuss the issue of smoking. In these places, they offered their perspectives on the cultural aspects of yarali' (tobacco) and the responsibilities associated with maintaining its traditions. The Cultural Mentors gave invaluable support, taking charge of recruitment, and facilitating meetings with informants, Elders and leaders prior to and during the study. In addition, they helped the author review the audio recordings from interviews before analysing, interpreting, translating and negotiating shared and attributed meanings of words and concepts. With their help, I gained an understanding of the history, and the rich culture and traditions of the Yolnu peoples concerning narali'. Buku-djulni! This article is dedicated to you both.

\section{Introduction}

In 2014 while managing a small primary health care mobile service in a remote location in the Northern Territory, and with a decade of experience in tobacco control leadership and advocacy in Aotearoa New Zealand (NZ) and Australia, I began work on a research project for my PhD. The project was called, 'Talking About Smoking in East Arnhem Land (EAL): Denormalisation, Stigmatisation and Leadership'. The study explored current tobacco control efforts in the region, and posed the questions: had the Indigenous peoples of EAL, the Yolnu, experienced feelings of marginalisation and stigmatisation as smoking had become increasingly unacceptable in Australian society? What views and opinions had they formed of

1 This paper is based on the experiences of the first author as she undertook data collection with the Yolnu peoples of East Arnhem Land, as part of her PhD research.

2 Dr Matire Harwood is a PhD supervisor for the first author and provided initial comments and feedback associated with aspects of Kaupapa Māori research. 
these experiences? How did this impact on the way they sought help to quit smoking? How had leadership been engaged and what were the views of Yolnu about smoking and tobacco?

My intention was to challenge tobacco control denormalisation strategies, which had in recent years become implicated with socioeconomic discrepancies in smoking prevalence because such approaches have historically had a greater impact on the better off (Bell, McCullough, Salmon, \& Bell, 2010). Evidence showed that mainstream anti-smoking interventions to reduce smoking rates amongst Indigenous peoples had not impacted effectively on smoking (Bond, Brough, Spurling, \& Hayman, 2012) but had contributed to the widening of health inequalities (Feldman \& Bayer, 2011). I wanted to disrupt the view that social control and social exclusion of smokers was acceptable in achieving more smoking cessation and to advocate for alternative approaches within Indigenous communities, with their disproportionately high prevalence of smoking, as a direct result of colonisation.

I understood that to effectively understand and engage with Indigenous smokers, the sociocultural context of Indigenous smoking and smoking cessation experiences needed to be considered - this meant listening to Indigenous smokers and their families, their views and insights. I wanted to use my knowledge of Kaupapa Māori Research (KMR) to explore the issues from a decolonising position, being critical of the power structures that have served to disadvantage Indigenous communities, and being mindful and respectful of Indigenous ways of knowing and being. I also wanted to affirm myself as wahine Māori (a Māori woman), with my own cultural practices and beliefs. These intentional choices influenced the research design and with the involvement of Cultural Mentors (DYM and RMN) and a Māori academic Matire Harwood with expert knowledge of KMR and the impacts of smoking on Indigenous peoples, I began the study in 2014. Of importance was my own practice of 'tika'3 and 'pono'4 values inherent in being a Māori woman and crucial to my role as an Indigenous researcher.

I did not realise when I began that I would re-evaluate my own understanding of the meaning of smoking and tobacco, nor did I imagine I would learn so much about the Yolnu culture, focused as I was on yarali' - but the two are interwoven. I am sharing this journey to encourage other Indigenous researchers especially those within my field of interest, to amplify Indigenous voices within the research academy, to challenge western power structures that privilege mainstream sensibilities and to advocate for Yolnu to have greater control and decision making in all aspects of their lives. Together, we can uphold an Indigenous research agenda that serves and informs the political liberation struggle of Indigenous peoples:

It is a struggle for development, for rebuilding leadership and governance structures, for strengthening social and cultural institutions, for protecting and restoring environments, and for revitalising language and culture. (Smith, 2005, p. 89)

\section{Background}

The Yolnu people of Australia are the traditional owners of large estates within Arnhem Land in the Northern Territory (NT), having occupied these areas for tens of thousands of years. With rich traditions, oral history and a dynamic, vibrant culture the Yolnu maintain many traditional customs and practises, and distinct languages. All Yolnu people belong to one of two basic divisions, or moieties, called Dhuwa and Yirritja. Yolnu moieties are exogamous, patrilineal and all-encompassing (Morphy, 2016). Everything in the Yolnu universe - Spirit Beings, plant and animal species, clan groups, areas of land and water are either Dhuwa or Yirritja and within each moiety, people belong to smaller groups

3 Tika = to be correct, true, upright, right, just, fair, accurate, appropriate, lawful, proper

4 Pono = be true, valid, honest, genuine, sincere 
called clans, each having its own language. Children belong to their father's clan (and moiety), while their mother belongs to another clan (of the other moiety). Clan members own areas of land and waters in common, however the relationship is much more complex than just 'owning', or even 'caring for', the land (Hutcherson, 1995). Rather, the Yolnu consider themselves as having come from the land, or of being the land, a familiar concept for Indigenous peoples and nations throughout the world, who seek to maintain a unique relationship with the earth, for the ongoing health and wellbeing of their communities and nations (Committee on Indigenous Health, 2002).

The Yirritja moiety are the Custodians of yarali' or tobacco and keepers of the narali' dance, songlines and stories. Tobacco arrived to the northern shores of Australia in the 1700s with the Macassans, and its use was associated with enhanced prestige amongst the Elders and male leaders who had limited access to supplies through trading (Mclntosh, 2013). Tobacco pipes were also acquired and were often incised or painted with totemic designs, transforming them into sacred items, the use of which could be restricted to initiated men (Toner, 2001). Donald Thomson (1901-1970), anthropologist and author of Economic Structure and the Ceremonial Exchange Cycle in Arnhem Land (1949), referred to the carefully moderated use of narali' amongst males observed:

In a society in which generosity and sharing were pre-eminent values, this strategy enabled a man to conserve his tobacco and the means of smoking it, while being able to avoid any accusations of meanness (Thomson, 1939, p. 89).

In more recent years, narali' has been integrated as 'a sacred part of culture and ceremony' (Kariippanon, 2014) and is described as mulwatj, which refers to anything that is culturally important (Toner, 2001). Today in Arnhem Land, it is possible to see Yolnu dancers performing segments of the Macassan song cycle with actions that 'beg' and 'ask' (the Macassans) for tobacco (Brady, 2013). The tobacco song is also used in funerals to dedicate a grave:

Performers are given small amounts of tinned tobacco with which they dance, rolling it between their hands, and at the end of the performance the tobacco is sprinkled into the open grave (Toner, 2001, p. 262).

Given the Yolnu's long association with narali', the integration of tobacco into culture and ceremony, and the effects of colonisation processes that used tobacco to pacify and control Indigenous peoples, it is no surprise that smoking has become ubiquitous and normalised within Yolnu communities. The effects and harms of smoking on Indigenous Australians are well documented (Clough et al., 2004; Clough, MacLaren, Robertson, Ivers, \& Conigrave, 2011; Kariippanon, 2014; MacLaren et al., 2010; Mulholland, 2008; Robertson, 2011; Stevenson, Bohanna, Robertson, \& Clough, 2013), however, the juxtaposition of the common or profane use of narali' and its spiritual and cultural aspects have not been fully explored or addressed in the context of tobacco control in Australia.

\section{Research Aims}

The study sought to explore from the Yolnu perspective the meanings of narali', and to identify Yolnu perceptions and experiences of quit smoking programs and policies, effective smoking cessation and what informants believed could be done to prevent young people and children from initiating smoking. These issues were explored during discussions with Yolnu participants, who acknowledged the historical and social context of narali' as an important introduced material culture, a unique locus within Australian, Aboriginal and Torres Strait Islander societies. 


\section{The Context}

East Arnhem Land (refer Figure 1) is one of the most remote regions of the Northern Territory.

Figure 1 Talking about Smoking in East Arnhem Land' research sites (in blue)

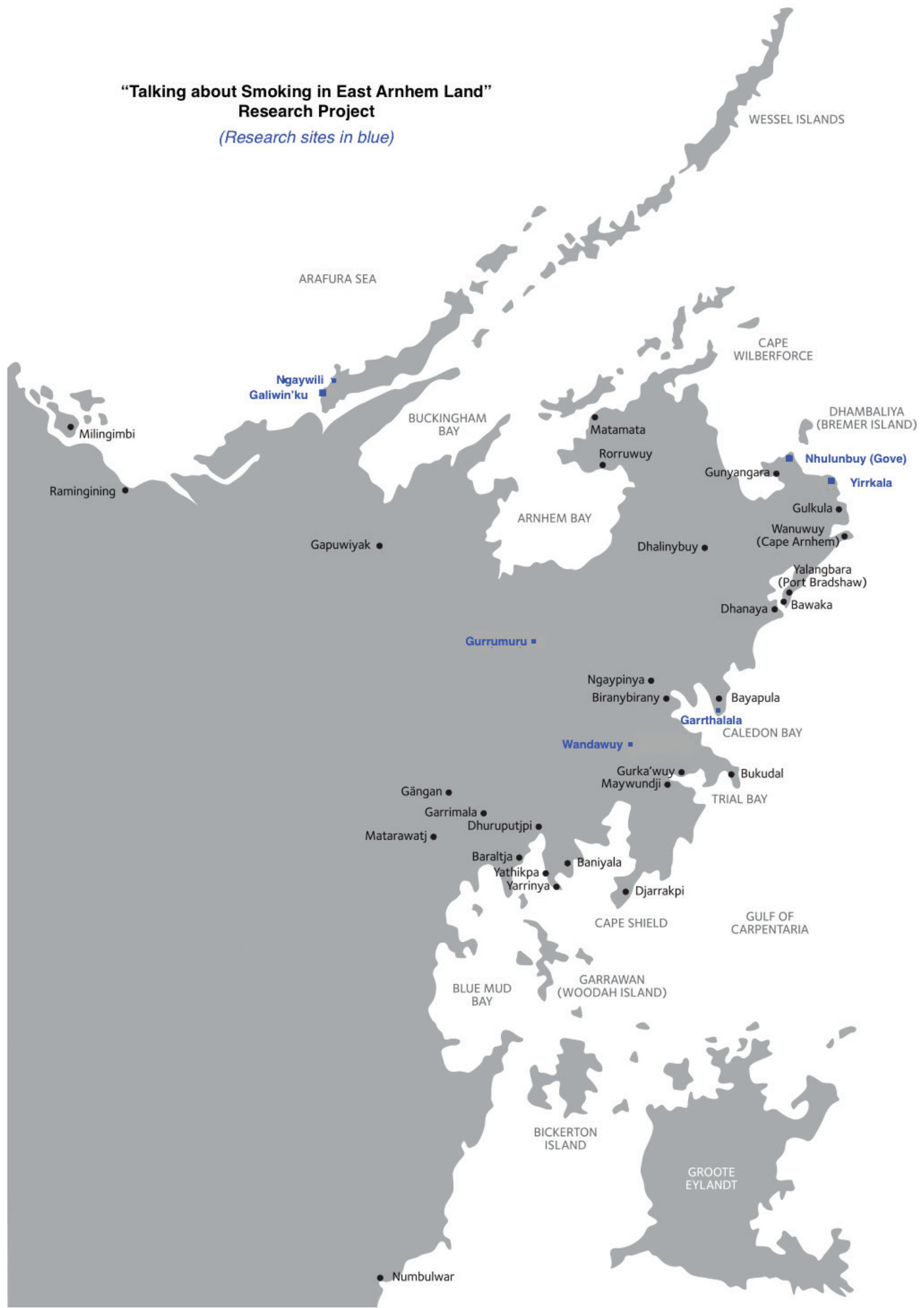


During the 1980s many Yolnu returned to their traditional lands to establish outstations or 'homelands' as part of a movement that saw many leaving the larger townships, often to escape social problems including alcohol and petrol sniffing (Morice, 1976). Today, Yolnu are actively asserting their sovereignty, over their lives and their estates (Trudgen, 2000) under their traditional Ngarra law (Gaymarani, 2011). A council of Tribal Elders and leaders make up the Yolnu Nations Assembly and in July 2016, they ratified a Constitution and declared:

We, as first peoples of Arnhem Land, have not been conquered. To this day we are a sovereign people. (Yolngu Nations Assembly, 2011, p. 1)

The Yolnu Nations Assembly has representatives from eight different provinces of the Arnhem region: Miwatj, Laynha, Raminy, Marthakal, Gärriny Gumurr-Rawarran, Gattjirrik and Midiyirrk and they aim to provide a governance organisation for Yolnu society. The intention of the Assembly is to remain consistent with the Madayin system of law (the traditional legal system of the Yolnu people); facilitate the interests and rights of the subjects of the Madayin system of law; ensure compatibility with the Australian Westminster system of Government; empower existing tribal governance jurisdictions; act as a diplomatic agency for outside groups; and, to enable good governance outcomes that empower and progress Yolnu society.

Elected leaders from the eight provinces hold authority for various roles within the Assembly including calling meetings, providing oversight, and representing on behalf of the Assembly. A well-known leader holding the position of Djawakmirr (person with authority to speak on behalf of the Assembly) is the Reverend Dr Djiniyini Gondarra. Gondarra is a Senior Elder of the Dhurili Clan Nation and Chairman of the Arnhem Land Progress Aboriginal Corporation who has called for recognition of the traditional law of the Yolnu people of Arnhem Land:

There is no recognition of the fact that we have assented to our law for many thousands of years and we still consider ourselves a sovereign people who belong to different Ringitj Nation States. (Commonwealth of Australia, 2012, p. 210)

The exploration of narali' as an introduced material culture and the impacts of smoking on Yolnu smokers and their families are addressed within this article in the context of the declared aspirations of the Yolnu Nations to be self-determining and sovereign. While these aspirations are key issues for the Yolnu, they are also applicable and of importance to Indigenous tobacco control researchers from other nations, who perceive smoking as a threat to health and wellbeing, and who also identify it as a barrier to Indigenous peoples reaching their full potential.

\section{Addressing researcher reflexivity}

I began the research as a member of the local health service, which afforded some distinct advantages. Access to the remote homeland communities remains at the invitation of local communities and/or organisations and as an employee of the latter, I was able to move freely around the region. This gave me time to approach Aboriginal organisations and their boards where I was hoping to conduct research, for their endorsement.

As an Indigenous Māori woman from Aotearoa New Zealand (NZ) and a guest in Arnhem Land, I was concerned with conducting Indigenous research that was 'ethically and culturally appropriate' (Botha, 2011, p. 314) and that was informed by Indigenous epistemology that acknowledged 'the interconnectedness of physical, mental, emotional, and spiritual aspects of individuals, with all living things and with the earth, the star world, and the universe' (Lavallee, 
2009, p. 23). My intent was to ensure that the study would be deliberately configured to privilege Indigenous voices, understanding the importance of centering the concepts and worldviews from their perspectives and for their purposes, rather than 'problematising' them, a seemingly Western obsession (Smith, 1999). When it came to voice, I was especially conscious that while I as an Indigenous person might have empathy for the Yolnu, it was their voices that needed to be heard (Rigney, 2003).

Although I was positioned with 'insider' status, by virtue of being Indigenous, and living and working in the local community, I had limited cultural and traditional knowledge, a risky proposition for undertaking local research. Seeking advice from local leaders and colleagues, I located a male Yolnu person who was willing to work with me as a Cultural Mentor and who helped with advice and guidance on cultural issues and gender-specific protocols.

The second Cultural Mentor (CM) to join the research was female and having met, we quickly became friends. Our visits to the communities together for data collection were very productive and enjoyable and later, in the comfort of my home, we would review the recordings, while I took notes of her comments and observations. I recorded these sessions and later sessions with the male CM, to analyse their contributions as an integral part of the research. Their incisive, informed comments were key to the process of data analysis and coding that I was engaged in.

As senior Elders and leaders they gave credibility to the research and during the period of 12 months while we were collecting data, informants spoken honestly and openly about their deep and abiding connection to narali'. Informants described in detail, the various roles and responsibilities of upholding culture and tradition especially those associated with funeral ceremony. I attribute the willingness of the Yolnu to communicate with me, directly to the presence of the CMs and I could not have conducted the research without them.

When I first visited EAL, I was adopted into the Yirritja moiety. Over time, I wass invited to a number of funerals, but had not felt comfortable to attend. As a Māori woman, my own cultural values required that I observe the kawa or protocols of: 'tangi', ${ }_{5}^{5}$ 'tapu', ${ }^{6}$ and 'noa'. ${ }^{7}$ This was not possible however as I was without a male to perform the role of 'taumata-korero'8 during 'powhiri' or 'tangi' encounters. I did not choose to disclose my reluctance to attend funeral ceremony to any of my Yolnu friends, for fear of giving offence. However, on one occasion at the direction of a senior woman, our whole organisation did attend and take part in a funeral. We were able to observe from the sidelines, the narali' bungul (dancing) and the narali' manikay (songlines). It was a moving occasion and later in privacy, I discreetly observed the cleansing and karakia that my culture requires after contact with a tupapaku. ${ }^{10}$

Growing up as part of a minority group in Aotearoa New Zealand the complexities of balancing diverse cultural expectations were not new to me, however, being an Indigenous researcher in Australia was. I was forced to regularly explore my 'insider' and 'outsider' status as a Māori woman living in an Indigenous community, which was not my own.

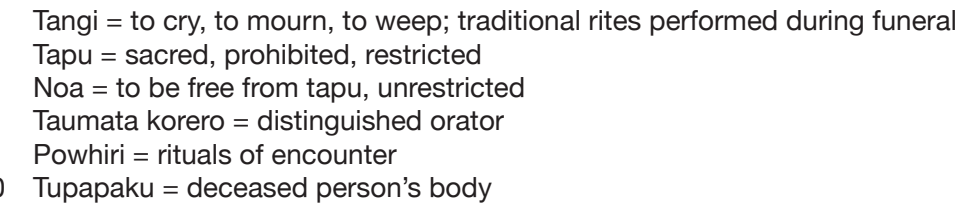


The term 'insider' has been used in social research and is replete with meaning. Seminal research from Kanuha (2000) explored the roles and challenges of 'insider', 'Indigenous', or 'native' research, from the perspective of being an Indigenous researcher undertaking work with one's own identity or cultural group. While an insider's position is not necessarily an unchallengeable 'true' picture, it represents one possible perspective.

Being Indigenous from another country did not necessarily produce greater insight into the lives and understandings of the Yolnu. However, it did give me access to observe, explore and interpret meaning from an Indigenous frame, based on first hand experiences. While authentic representation of the contexts and practises of Yolnu regarding narali' were best accessed by Yolnu themselves (Bainbridge, Whiteside, \& Mc Calman, 2013), I hoped that by working closely and collaboratively with the CMs we would bring new perspectives to the discussion, genuinely reflecting the concerns of the Yolnu. Accepting the limitations of my 'insider'/'outsider' realities was part of a dynamic process of learning and reflecting.

The personal experience of being tangata whenua ${ }^{11}$ and growing up on lands that our tribe has occupied for a thousand years, has always been a source of strength to me, providing my whanau (family and extended family) and I with a sense of belonging and confirming our identity as Māori. I understood at a fundamental level the enormous value that the Yolnu hold for their place in the universe, to be guarded and protected for the next generations. A wellknown Māori proverb reminds us:

Whatu ngarongaro he tangata, toitu te whenua.

People perish, but land is permanent. (Williams, 2008, p. 1)

I rationalised that what strengthens and promotes a sense of belonging as Indigenous people is our knowledge of who we are as tangata whenua or people of the land. Mason Durie (Durie, 2004a), quoting Indigenous sources, describes the most defining element of indigeneity as a strong sense of unity with the environment:

People are the land and the land is the people. We are the river, the river is us. (Durie, 2004b, p. 4, 18)

Knowing where I belonged helped me to find harmony in balancing my role as a researcher and my obligations as an Indigenous woman living as a guest in another country.

\section{Decolonising the denormalisation debate}

Coming to formal education late in life, I recall engaging with historic evidence of racism in Aotearoa NZ. Having grown up in a small, rural, predominantly Pakeha (New Zealander of European descent) community, I had my own memories of inequities and injustices, personally and involving my family and extended family, with the justice system, our traditional lands and our aspirations to be self-determining.

A critical review of the history of colonisation and the breaches of the Treaty of Waitangi that had begun almost immediately after signing (Belich, 2007; Orange, 2015), had the effect of validating my experiences and those of my parents, who were whipped for speaking their language at school. My studies at university revealed the extent of institutionalised racism and discrimination against Māori in Aotearoa NZ from first contact, something that even today

11 Tangata whenua are people born of the whenua, i.e. of the placenta and of the land where the people's ancestors have lived and where their placentas are buried. 
many Pakeha deny, as it is contrary to the popular notion that Aotearoa NZ is a 'bi-lingual' utopia, where we all just get along (Albury, 2015). What has now been established is the fact that it is largely through societal systems of racism that material and symbolic, for example political privilege (Yin, 2016), are maintained. The experiences of Māori reflect those of other Indigenous peoples, with disparities across a broad range of indicators, most profoundly health, as a result of and directly related to the colonisation experience (Reid, Taylor-Moore, \& Varona, 2014):

Indigenous peoples remain on the margins of society; they are poorer, less educated, die at a younger age, are much more likely to commit suicide, and are generally in worse health than the rest of the population. (International Working Group on Indigenous Affairs (IWGIA), 2006, p. 10)

Complicit in the process of colonisation is the use of tobacco as a tool for trade, influence, and ultimately control of Indigenous peoples' resources and their labour. Called the 'gift from a distant land' (Reid \& Taniwha, 1991, p. 1) tobacco was used to ensnare Māori, creating dependency and addiction. The disproportionately high smoking prevalence by Māori today is testimony to the effectiveness of its initial introduction by colonists, reinforced by postcards and advertisements, which portrayed Māori tobacco use as a social norm (Barnett, Moon, \& Kearns, 2004; Monin, 2001). This led to smoking becoming entrenched into the Māori way of life (Broughton, 1996). The speed with which this was achieved also reflects Māori society at the time with its well-ordered social structures, and strong kinship ties which facilitated the widespread sharing and use of tobacco.

In 2009, key Māori leaders leveraged political influence to advocate for an inquiry into the impacts of the tobacco industry on Māori, and in 2010, a Māori Select Committee Inquiry was established (Ministry of Health, 2010). Following this milestone, with optimism high, an ambitious goal to make NZ smokefree by 2025 was set by a cooperative of mainly nonMāori tobacco control advocates whose organisations later became the main recipients of government funding to achieve this, at the expense of Kaupapa Māori organisations such as Te Reo Marama and Te Hotu Manawa Māori (Confidential Source, 2009) both of which lost their major tobacco control contracts. In a recent book well-known investigative journalist Nicky Hager (2014) suggests these cut backs in Māori tobacco control were influenced by interference from a tobacco industry lobbyist with strong links to the Ministry of Health, and who had unrestricted access to run a smear campaign directed at these organisations and their representatives, through a blog (Slater, 2009).

Today, it seems that little progress has been made in reducing smoking prevalence amongst Māori and a review of the Smokefree Aotearoa 2025 goal showed that this key indicator will be missed by a substantial margin (Ball, Stanley, Wilson, Blakely, \& Edwards, 2016). The result is hardly surprising given the lack of direct support to Māori tobacco control following the inquiry, however, the evidence also points to a failure by the NZ government at the time to adequately fund tailored and targeted approaches to smoking cessation interventions for Māori despite the urgent need.

Unfortunately, research has shown that there is a uniform lack of political will to address the needs of Indigenous smokers in other countries (DiGiacomo et al., 2011), distinguished by a failure to address the social-cultural contexts in which smoking is occurring or the use of culture as a strengthening effect on identity (Bond, 2007). Rather, we have witnessed over time, how government processes have tended to favour mainstream, whole of population approaches and especially so within the context of tobacco control, which seems dominated by a focus on denormalising smoking. 
The denormalisation strategy in its original form used advocacy and policy change to shift social norms and eliminate the tobacco industry's influence at the local level (California Department of Health Services, 1998). Today, denormalisation has become strongly associated with stigmatisation. That is the spoiled identity associated with Goffman's theory of stigma from 'a whole and usual person to a tainted, discounted one' (Goffman, 1963, p. 3), has extended beyond the tobacco industry, and has alighted upon those who continue to smoke - many of whom are Indigenous. Today, tobacco control denormalisation strategies utilise increasing social pressure to quit through marketing campaigns, and increasingly stricter smoking restrictions, bans and regulations for public and private spaces (California Department of Health Services, 1998), all being delivered as part of a 'one-size fits all' dogma.

I entered public health and tobacco control in 2006 in NZ and immediately encountered fervent, well-meaning tobacco control advocates, whose main efforts were concerned with denormalisation strategies, all too often adopting a blaming and negative view of Māori smoking, with little regard for finding culturally appropriate solutions to address the issue. Despite the presence of persistent health disparities amongst Māori because of smoking, few acknowledged the origins of smoking within the context of colonisation.

I have because of these experiences remained strongly critical of these strategies within the context of Indigenous smoking. While widespread reductions in smoking prevalence have been achieved globally, these efforts have also contributed to widening health disparities with a marked social gradient emerging in smoking behaviour over the past several decades (Bayer, 2008a). Indigenous peoples and those at the lower end of the social stratification system in economically advanced societies such as NZ and Australia continue to smoke - and those who have more income and education are less likely to do so.

Credit must be given to many authors who continue to raise the question of denormalisationassociated stigma in tobacco control (Bayer, 2008a; Bayer \& Feldman, 2012; Bayer \& Stuber, 2006) and who have posited, 'Not can we, but should we?' (Bayer, 2008b, p. 463). They observe that increasing inequalities and the use of restrictive and burdensome public health measures designed to further limit prevalence of tobacco use will most affect those at the bottom of the social ladder - where the majority of Indigenous populations are represented. Investigating whether the initiatives and programs introduced to the Yolnu communities where I lived and worked became of importance and interest to me in the context of these strategies, and was fundamental in prompting me to take up $\mathrm{PhD}$ studies.

\section{Health disparities in Arnhem Land}

The experiences of the Indigenous peoples of Australia through colonisation processes are characterised by greater impacts and losses in comparison to NZ, because of harsher government and settler interventions over longer periods of time (Council for Aboriginal Reconciliation, 1994; Department of Territories, 1967; Rowley, 1970; Tatz, 1979). The effects on Aboriginal and Torres Strait Islander peoples have been well documented and in recent years, health researchers have clearly illustrated a powerful relationship between the health status of individuals or collectives and social, political and economic circumstances (Marmot, 2011; Marmot \& Wilkinson, 2001). Most significant of these colonial impositions has been the forced removal of Indigenous Australians from their families (Young, 1998), from their communities, their land and their birthright connections to the land (Gardiner-Garden, 1999). Acknowledgement of the impacts that invasion, imperialism, colonisation, research and policy have had on the Indigenous peoples of Australia (Sherwood \& Edwards, 2006) is crucial in addressing the persistent, pervasive disparity in health outcomes today. 
The history of tobacco as a tool to assist in the colonisation of Australia is similar to NZ, however, there are some unique differences. Historically in Central Australia, pituri leaves containing nicotine, were chewed for their narcotic effect (Ratsch, Steadman, \& Bogossian, 2010) and as described previously, tobacco first came with the Macassans to Arnhem Land. With the establishment of mission stations in Arnhem Land in the mid-1900s, Yolnu gained regular access to tea, flour, sugar and tobacco in exchange for their work, a practice reinforced as part of government policies (Macknight, 1976).

One of the most confronting aspects of living in East Arnhem Land, was the regularity in the number of funerals that were held by the Yolnu, often following illness from advanced and latestage chronic conditions. Data reported in 2011 (Australian Institute of Health and Welfare, 2011) showed that the difference in estimated life expectancy by Indigenous status is greatest in the Northern Territory, where male Indigenous life expectancy is 14.2 years lower than for non-Indigenous males. The largest differential in mortality rates is in age groups from 25-54 years, where Indigenous rates are 4-5 times higher than for non-Indigenous persons.

Smoking is the leading risk factor for Indigenous Australians, and accounts for $12.3 \%$ of the burden of disease, more than any other risk factor such as alcohol and illicit drugs combined. Smoking is related to cardiovascular disease, accounting for about $25 \%$ of all Indigenous deaths; and to cancer, the next most common cause of death among Indigenous people (20\%, with lung cancer representing 4.9\%) (Scollo \& Winstanley, 2015).

In Arnhem Land remote communities, smoking prevalence between $68 \%$ to $83 \%$ in men and $65 \%$ to $73 \%$ in women have been reported with little change since the mid-1980s (Clough et al., 2011).

\section{Methodology and Methods}

In adopting a grounded theory methodology for the study, I sought to disrupt and challenge the many voices of tobacco control researchers and advocates who continue to maintain strategies of denormalisation, increasing restrictions, and stigmatisation of smoking and smokers despite the implications for Indigenous peoples and other disadvantaged groups (Thompson, Pearce, \& Barnett, 2007).

The grounded theory methodology seeks out and conceptualises the latent social patterns and structures through the process of constant comparison of concepts (Glaser, 1978) derived from interviews with individuals and on some occasions, groups of informants. The method starts with the use of an inductive approach to generate substantive codes from the data, later developing theory to guide where to go to next and which, more-focussed, questions to ask. This method is ideal for 'exploring integral social relationships and the behaviour of groups where there has been little study of the contextual factors that affect individuals' lives' (Calman, 2006, p. 3). The final product of a grounded theory study is the development of a theory or theoretical framework.

I began by recording interviews with Yolnu and Napaki/Balanda (non-Indigenous) participants and later transcribed these. Of the 22 Yolnu who were interviewed, ten participants chose to speak mostly in English. I worked with the CMs who gave me advice and guidance prior to the interviews, and attended the sessions. The CMs translated the interview questions into a Yolnu language for every session, and then interpreted answers for me to record. When I spoke during the sessions, it was in English and the CMs provided translations when needed. 
During the transcribing process, and where participants had spoken in a Yolnu language, one of the two CMs and I reviewed the recording later, often in the afternoon on our return from the community. Comments made by the CMs and insight offered were also recorded, transcribed and analysed later with their permission.

The grounded theory methodology gave me the tools to explore possibilities and propose interpretations that challenged the taken-for-granted notions of western tobacco control research. Staying close to and being grounded in the data, enabled me to explore and make sense of the informants' perspectives and to value these as useful and beneficial, seen from the point of view of the Indigenous peoples involved (Porsanger, 2004).

Qualitative interviews were conducted with informants in eight communities by the researcher (MT), with the support of Cultural Mentors. Interview questions focused on participants' knowledge, experiences and views of narali' including perspectives of local programs. The researcher encouraged them to 'tell their stories' about narali', an Indigenous style of conversation consistent with local culture (Bainbridge et al., 2013, p. 284).

\section{Sampling and Permissions}

Engaging and consulting with the Yolnu communities firstly required a process involving local health service managers, Aboriginal Health Workers (AHWs) and the CMs, to determine which communities would be interested in participating.

I was then permitted to travel with health service staff to meet the local Elders, where I discussed the research, answered any questions they had, and then requested permission to interview participants at a later date. I returned to the community one week later with a CM and we visited their contacts, or met clients at the clinic, who came for interviews. Interviews were conducted after participants signed an informed consent form. Open-ended questions were used throughout the interviews and were aimed at exploring from a Yolnu perspective, values, perceptions, beliefs and attitudes to yarali', from a cultural and historical perspective.

I visited eight communities and conducted interviews with AHWs, administration staff (all Yolnu) and with community members. Participants communicated their preferences on the location and setting of these interviews, depending on where they felt comfortable. Some interviews were held on the clinic veranda (if preferred by the informant) or in a consult room - a family member would often be present. Some of the Yolnu employees that were recruited wanted to come to my house, so I conducted interviews there as well.

Prior to this, I obtained formal permission in writing from three Aboriginal corporations through their Boards and/or CEOs or managers, who provided a letter of support, and gave permission to interview their employees. In later discussions with researchers who had experienced barriers in recruiting research participants, I began to more fully appreciate the benefit of working and living in these communities. Ethics approval (HREC 2014-2169) was obtained from the Health Research Ethics Committee, Charles Darwin University and Menzies School of Health Research, in 2014. This was a relatively simple process once I had received permission and letters of support from the heads of these regional organisations and their boards. However, in keeping with local custom, I always sought permission first from the Elders of the communities, and would not have proceeded without their approval. 


\section{Analysis}

Following transcribing, I conducted line-by-line coding of text using NVivo 10, a data analysis software program. This type of coding begins with naming small blocks of text in an inductive form of data analysis, thought to be more "grounded" in what participants have actually said (Berg, 1995; Lavallee, 2009). I began data analysis immediately after the first interviews began with a priori parent nodes. Over time, these initial codes changed as more data was analysed. I supplemented the coding with memo writing, reflecting and describing any changes in my thinking. Further analysis resulted in additional and amalgamated codes, to better describe concepts derived from the data. I made comparisons between the data, and the codes, and used memo writing to explore lines of inquiry to probe in subsequent interviews.

While it was my original intention to undertake theoretical sampling, my cohort of participants was somewhat limited. Once interviews had begun, we were able to use snowball sampling, finding new participants from communities where we had already been working in. This meant that we had sufficient informants for data collection and analysis and I reached saturation or the point where there were no new concepts emerging from participants with around 22 Yolnu. At this point I had over 50 codes, and eight parent codes.

By this stage, I had become concerned that the voices of informants had been attenuated by the systematic 'line by line' analysis and I was anxious to uphold an Indigenous research agenda. By breaking the text into small pieces and then aggregating into one whole, I felt that I may have lost sight of the unique and individual characteristics and voice of the informants (Lavallee, 2009). Addressing this, I went back to the original interview transcripts and re-read each one as a whole, comparing and contrasting participant perspectives, writing higher level summaries and checking against the nodes to ensure that I had represented all the recurring and important (based on their context) concepts from the data. This process helped me to distil the data from 50 codes and eight parent codes, down to a total of 13 categories, which I was able to compress into three main themes. I was satisfied that I had not only represented the informants' voices, but I had also reached theoretical saturation where all of the concepts being developed were well understood and could be substantiated from the data (Sbaraini, Carter, Wendell Evans, \& Blinkhorn, 2011, p. 3).

I approached the next stage of my study, the development of a theoretical model, with enthusiasm. Drawing on a unique Yolnu metaphor of 'two-way learning' (Morphy, 2002, p. 8), I created a visual depiction of a mutually beneficial exchange of cultural knowledge, between the Yolnu and those involved in tobacco control in the region. Similar to the concept of 'bothway education' (Australian National University, 2017, p. 1) the approach recognises the relative autonomy of Yolnu and European systems of knowledge. As Morphy observes,

It advocates teaching them separately, but in an environment where they can come together for mutual benefit. The philosophy was built around the metaphor of ganma, the process whereby fresh water and saltwater come together and become highly potent. (Morphy, 2016, p. 337)

I envisaged that this approach would lead to better communication and improved understanding, in a space created specifically for Yolnu voices to be heard, and listened to. In such a setting, the resources and decision-making power needed to create culturally appropriate interventions and solutions would be accessed and shared, toward achieving a common goal of improving Yolnu health outcomes, through smoking cessation. 


\section{Summary of Research Findings}

The focus of this article is on my research methods and methodologies not on the research findings. The results of the interviews will be examined in more detail elsewhere. However, a brief overview of the findings is provided to inform the reflection on my approach to this research.

Informants freely expressed their views on issues such as smoking restrictions, policies in the workplace and tobacco price increases. Surprisingly very few Yolnu described feelings of marginalisation or stigma in association with smoking - in the Yolnu world, smoking is an everyday occurrence, and it is only when Yolnu come into contact with the wider environment that it becomes an issue such as when they visit hospitals or have to attend work or meetings.

Comprehensive mainstream tobacco control programs have traditionally sought to address smoking at every level of society including through social influence, environmental restrictions and price increases on tobacco. Yolnu informants commented that these measures had been somewhat effective (given that some had experienced feelings of shame) but that the mainstay of price increases and smoking restrictions, were largely ignored.

Many smokers who had been able to quit, had done so abruptly as a result of a health scare, or imminent hospitalisation for treatment - and they had achieved smoking cessation with little support, other than being told they needed to quit by a health professional. Some of the Yolnu who were employed as health workers had not been offered support to quit smoking, nor had they requested help - but each of them expressed a desire to quit smoking, and disappointment that they had not been able to achieve smoking cessation.

Rather than drive toward the goal of 'policy and programs to improve the health of all Australians by eliminating or reducing their exposure to tobacco in all its forms' (Department of Health, 2017), Yolnu intended to continue their narali' culture and traditions associated with caring for family, family leadership and responsibilities. Recognising that yarali' would always be treated as mulwatj or precious with respect to traditional culture, both smokers and non-smokers agreed that it would remain 'a sacred part of culture', for all generations (Miwatj Health Aboriginal Corporation, 2014).

Although cultural obligations were associated with narali', differences from the act of smoking tobacco were articulated by Yolnu informants; smokers, and non-smokers reiterated that Yolnu can celebrate and participate within the narali' ceremonies, without being a smoker. No immediate interest in putting aside these cultural aspects and obligations of narali', were reported by Yolnu informants.

\section{Discussion}

The intention to address social justice and to explore the issue of smoking within the context of the history and traditions of the Yolnu peoples of Arnhem Land was made at the beginning of this study, and this decision influenced the research design and methodology. Yolnu informants interfused their beliefs and values including those that of yarali' which have been integrated into funeral rites and ceremonies, throughout their discussions and interviews. Analyses of these aspects of Yolnu practices provide insight into their socio-cultural environment and reveal a stark contrast between current tobacco control efforts within the region and the aspirations of the Indigenous peoples for their families and communities to address the issue of smoking. Within the domain of tobacco control and public health, denormalisation practices that postulate increasing measures of social control and social exclusion of smokers, and that ignore the history of colonisation where tobacco was used as a tool to control, are incongruent with Indigenous histories, cultures and traditions, especially for the Yolnu peoples of Arnhem Land. 
In every community where this research was conducted, smokers described their lives, attitudes, beliefs and values in terms of their connection to their families and clans. A smoker was not perceived as a lone individual, but rather as a vital and integral part of their family, with roles and responsibilities acknowledged and well-described. This is contrary to the view of health practice which is concerned with an individualist approach, and which does not acknowledge remedies that are associated with land, language, identity and spirituality, but focuses on discreet interventions such as, eating better foods or giving up smoking as a panacea for addressing poor health outcomes. This approach has been criticised as it 'effectively blames the victim, disempowers the victim, and/or entrenches the very conditions that create adverse health outcomes' (Bond, 2007, p. 85).

The findings of this study represent a new opportunity for those working with the Yolnu to engage in ways that are culturally responsive, sensitive to local needs and norms, and respectful in their approaches. Research has shown that these methods are most likely to be effective (Gould, 2014; Gould, McEwen, Watters, Clough, \& van der Zwan, 2013; Johnston \& Thomas, 2010; Stevenson et al., 2013). Increasing the involvement, engagement and ownership of Indigenous communities in finding their own solutions, may challenge the status quo in this sector, however, new elements for discussion in the context of tobacco control are urgently needed.

The notion of self-determination and being in control of one's future, resources and lands, and able to act sovereignly is challenged by the act of smoking, and many Yolnu smokers were eager to quit, but felt that they lacked the support or capacity to do so, despite numerous attempts. Health indicators show that Indigenous Australians are over-represented by negative health statistics, bear a greater burden of disease, and experience disproportionately more losses through premature death from smoking related diseases. Given that these health outcomes are preventable, the research sought to explore alternative and acceptable approaches to support the Yolnu to quit smoking and to prevent more Yolnu children and young people from initiating smoking.

The idea that this research would benefit Yolnu people, helped me to remain firm in my resolve to advocate in this space for better access to resources (Tane, 2014). Reciprocity and responsibility were key values that also helped me to remain resolute in presenting the findings from my research at national and international conferences (Tane, 2015 \& 2016) to raise awareness and to call for greater understanding within the tobacco control sector. I did so because I owe a debt to those Yolnu who participated in the research, for allowing me to conduct research within their country. They own the results of this study, and should be the primary recipients of any benefits, such as redirected resources, should these eventuate.

As an Indigenous researcher, the issue of ownership was a key concern, as it is for other Indigenous researchers. Moreton-Robinson (2016) discusses the involvement of nonIndigenous scholars with Indigenous peoples, studies or issues, and observes that while nonIndigenous scholars can participate with Indigenous analytics, they cannot by themselves, produce them. Smith (1999) recognises that there are 'powerful groups of researchers ... whose research paradigms constantly permit them to exploit Indigenous peoples and their knowledges' (p. 17). She advocates for Indigenous researchers and communities to have control of any studies involving Indigenous peoples. Rigney (2001) has argued that an Indigenist approach to research is formed around the three principles of 'resistance, political integrity, and privileging Indigenous voices' (p. 8). He connects research to liberation and to the history of oppression and racism. 
By conducting my inquiry in these remote locations firstly as a local employee, a resident, and an Indigenous person, I gained entry into the local social and cultural context. By meeting with informants in ways that were culturally known and accepted, working collaboratively with the CMs in the preferred language of the people, and immersing myself in the context of community, I was able to recruit sufficient numbers to inform the research. What the people shared with us, I recorded and later analysed, and the findings were fed back to the communities via the health services. This process served the purpose of advocating on behalf of the Yolnu for what they considered to be solutions for addressing smoking, and its harms. It was also a means of honouring the voices of those who had taken part and acknowledging their ownership over their own information and knowledges. Having set my goal to uphold an Indigenous agenda, I re-affirmed my own identity as a Māori woman and gained invaluable insight in my journey as an Indigenous researcher.

These actions were deliberate as a means of challenging the Western research academy with its legacy of studying Indigenous peoples as outsiders: 'Indeed, many of the basic disciplines of knowledge are implicated in studying the Other and creating expert knowledge of the Other' (Smith, 2005, p. 87). As Smith (1999) wryly observed, 'They came, They saw, They named, They Claimed' (p. 80). We Indigenous researchers are always involved in a struggle to ensure that the Indigenous informants and participants of our research remain central in our focus, and that they are not excluded from discussions concerning who has control over, 'the initiation, the methodologies, evaluations, assessments, representations, and distribution of the newly defined knowledge' (Denzin, 2010, p. 298). The decolonisation project continues to challenge such practices.

The research represented an opportunity to explore alternative approaches by drawing insight and understanding from the perspective of the Yolnu, reaffirming the need for approaches in tobacco control that encompass cultural strengths, identity and traditions. Aspirations for sovereignty and self-determination continue to be articulated at a political level amongst the Yolnu leaders of EAL, and this is unlikely to change, despite a relatively recent history of invasion, imperialism and colonisation. Smoking tobacco as a separate act from its traditional use in Yolnu ceremonies directly challenges the ability of Indigenous peoples to reach their full potential in terms of their health and wellbeing. While connections to culture and country are essential to the ongoing wellbeing of the Yolnu the early onset of chronic diseases and deaths because of smoking, continue to harm families and clans, often leaving them destitute when Elders and leaders pass away prematurely.

Those Yolnu participants who contributed to the research did so openly and willingly, and by their actions created expectations of reciprocity and a responsibility to share their views widely. From this perspective, I acknowledge an ongoing obligation to privilege the voices of the people from these communities, to speak up and support what they say and to advocate on their behalf, which is consistent with upholding an Indigenous research agenda. 


\section{Conclusion}

In seeking to establish and maintain an Indigenous research agenda in this study, I sought to contribute to more meaningful discussions within the tobacco control sector about the use of diverse approaches to support Indigenous smokers to quit. I sought to gain insight into the lives and meanings of the Yolnu with regard to narali' and to question their needs and desires for improving health. I believed that this study would lead to finding ways to engage respectfully and intentionally, working collaboratively within the socio-cultural and political environment of East Arnhem Land. I wanted to diverge from the well-favoured denormalisation approaches within tobacco control that I consider as often inconsistent for working with Indigenous communities and to use a decolonised research methodology to reflect Yolnu perspectives. The aim was not to compete with or replace the Western research paradigm but as Porsanger (2004) describes, 'to challenge it and contribute to the body of knowledge of Indigenous peoples about themselves and for themselves, and for their own needs as peoples, rather than as objects of investigation' (p. 105).

The rich diversity of Yolnu insight and cultural knowledge produced fertile ground for new learning and their dedication to the cultural and historical aspects of narali' was palpable. Their views have informed a re-evaluation of my own understanding of the meaning of smoking and tobacco. Of importance is that while the Yolnu affirm the importance of narali' within the culture and traditions of their ceremonies, a distinction is made between customary use and the act of smoking. An understanding of the dichotomous nature of the relationship between the Yolnu and yarali' should remain at the centre of future tobacco control efforts in the region.

\section{Acknowledgements}

I would like to acknowledge the following important contributors to this article: Rita Mukuruk Ngalmi and David Yangarriny Munyarryun. I am so grateful to have spent time working with you both and to have been guided and supported throughout this research, and during the years that I was living in Arnhem Land.

I would also like to acknowledge the following organisations and their leadership, for their support: Jeff Cook, Laynhapuy Health Service, Miwatj Aboriginal Health Service and Marthakal Homelands Health Service.

Special acknowledgement and thanks to my two PhD supervisors from Menzies School of Health Research and Charles Darwin University: Prof Dr David Thomas and Dr Marita Hefler. 


\section{References}

Albury, N. (2015, June 8 2015). Embracing Indigenous Language: the Kiwis just do it better. The Conversation. Retrieved from https://theconversation.com/ embracing-indigenous-languages-the-kiwis-just-do-it-better-42045

Australian Institute of Health and Welfare. (2011). Life expectancy and mortality of Aboriginal and Torres Strait Islander people. Canberra, ACT: Australian Institute of Health and Welfare.

Australian National University. (2017). About 'both ways' education: Incorporating Indigenous knowledge into your teaching. Retrieved 9 April, 2017, from http://livingknowledge.anu.edu.au/html/ educators/07_bothways.htm

Bainbridge, R., Whiteside, M., \& McCalman, J. (2013). Being, Knowing, and Doing: A Phronetic Approach to Constructing Grounded Theory With Aboriginal Australian Partners. Qualitative Health Research, 23(2), 275-288.

Ball, J., Stanley, J., Wilson, N., Blakely, T., \& Edwards, R. (2016). Smoking prevalence in New Zealand from 1996- 2015: a critical review of national data sources to inform progress toward the Smokefree 2025 goal. New Zealand Medical Journal, 129(1439), 11-22.

Barnett, R., Moon, G., \& Kearns, R. (2004). Social inequality and ethnic differences in smoking in New Zealand. Soc Sci Med, 59(1), 129-143.

Bayer, R. (2008a). Stigma and the ethics of public health: not can we but should we. Soc Sci Med, 67(3), 463-472. doi: 10.1016/j.socscimed.2008.03.017

Bayer, R. (2008b). What means this thing called stigma? A response to Burris. Soc Sci Med, 67(3), 476477. doi: $10.1016 /$ j.socscimed.2008.03.024

Bayer, R., \& Feldman, E. (2012). Tobacco control in industrialized nations: the limits of public health achievement. Public Health Reviews, 33, 553-568.

Bayer, R., \& Stuber, J. (2006). Tobacco control, stigma, and public health: rethinking the relations. American Journal of Public Health, 96(1), 47-50. doi: 10.2105/AJPH.2005

Belich, J. (2007). Making Peoples. United Kingdom: Penguin.

Bell, K., McCullough, L., Salmon, A., \& Bell, J. (2010). 'Every space is claimed': smokers' experiences of tobacco denormalisation. Sociol Health IIIn, 32(6), 914-929. doi: $10.1111 / \mathrm{j} .1467-9566.2010 .01251 . x$

Berg, B. (1995). Qualitative research methods for the social sciences (2 ed.). Boston, MA: Allyn \& Bacon.

Bond, C. (2007). "When you're black, they look at you harder": Narrating Aboriginality within Public Health (PhD). Brisbane, QLD.: University of Queensland.

Bond, C., Brough, M., Spurling, G., \& Hayman, N. (2012). 'It had to be my choice' Indigenous smoking cessation and negotiations of risk, resistance and resilience. Health, Risk \& Society, 14(6), 565-581.

Botha, L. (2011). Mixing methods as a process towards indigenous methodologies. International Journal of Social Research Methodology, 14(4), 313-325.

Brady, M. (2013). Drug substances introduced by the Macassans: the mystery of the tobacco pipe. In M. Clark \& S. May (Eds.), Macassan History and Heritage: Journeys, Encounters and Influences (pp. 141-158). Canberra, ACT: ANU ePress.

Broughton, J. (1996). Puffing up a storm. Volume 1: "Kapai te torori" Dunedin: University of Otago, Te Ropu Rangahau Hauora Māori o Ngai Tahu, 1. 
Buku-Larrnggay Mulka Centre (Cartographer). (2016). Location of north-east Arnhem Land and the Yirrkala region. Retrieved from http://www.artgallery.nsw.gov.au/media/uploads/ images/2013/12/10/Yirrkala_region.png

California Department of Health Services. (1998). A Model for Change: the California experience in Tobacco Control (T. C. Section, Trans.). Sacramento, CAL: California Department of Health Services.

Calman, L. (2006). What is Grounded Theory? Paper presented at the Manchester 1824, Manchester, UK. http://hummedia.manchester.ac.uk/institutes/methods-manchester/docs/gt.pdf

Clough, A., D’Abbs, P., Cairney, S., Gray, D., Maruff, P., Parker, R., \& O’Reilly, B. (2004). Emerging patterns of cannabis and other substance use in Aboriginal communities in Arnhem Land, Northern Territory: a study of two communities. Drug Alcohol Rev, 23, 381-390.

Clough, A., MacLaren, D., Robertson, J., Ivers, R., \& Conigrave, K. (2011). Can we measure daily tobacco consumption in remote indigenous communities? Comparing self-reported tobacco consumption with community-level estimates in an Arnhem Land study. Drug Alcohol Rev, 30(2), 166-172.

Committee on Indigenous Health. (2002). Indigenous Peoples' Health: A briefing paper for the permanent forum on Indigenous issues. The Geneva Declaration on the Health and Survival of Indigenous Peoples. New York: United Nations Permanent Forum on Indigenous Issues.

Commonwealth of Australia. (2012). Recognising Aboriginal and Torres Strait Islander Peoples in the Constitution: Report of the Expert Panel.

Confidential Source (2009, 4 August 2009). [Email re: Aukati Kai Paipa Contract].

Council for Aboriginal Reconciliation. (1994). Key Issue Paper No. 4: Sharing History. Canberra, ACT: Australian Government Publishing Service.

Denzin, N. (2010). Grounded and Indigenous theories and the politics of pragmatism. Sociological Inquiry, 80(2), 296-312.

Department of Health. (2017). Tobacco Control. Retrieved 5 September, 2017, from http://www.health. gov.au/tobacco

Department of Territories. (1967). The Australian Aborigines (pp. 48-61). Canberra, ACT: Department of Territories.

DiGiacomo, M., Davidson, P., Abbott, P., Davison, J., Moore, L., \& Thompson, S. (2011). Smoking cessation in indigenous populations of Australia, New Zealand, Canada, and the United States: elements of effective interventions. Int J Environ Res Public Health, 8(2), 388-410.

Durie, M. (2004a). Understanding health and illness: research at the interface between science and indigenous knowledge. International Journal of Epidemiology, 33, 1138-1143.

Durie, M. (2004b). 5th APEC Research and Development Leaders Forum: Exploring the interface between science and Indigenous knowledge. Paper presented at the Capturing Value from Science, Christchurch, NZ.

Feldman, E., \& Bayer, R. (2011). The Triumph and Tragedy of Tobacco Control: A Tale of Nine Nations. Annual Review of Law and Social Science, 7(1), 79-100.

Gardiner-Garden, J. (1999). From Dispossession to Reconciliation: Research Paper 27. Canberra, ACT: Social Policy Group.

Gaymarani, G. (2011). An introduction to the Ngarra law of Arnhem Land. Northern Territory Law Journal and Reports, 1, 283-304. 
Glaser, B. (1978). Theoretical sensitivity: Advances in the methodology of grounded theory: Sociology Press.

Goffman, E. (1963). Stigma: notes on the management of spoiled identity. New York: USA: Simon \& Schuster Ltd.

Gould, G. (2014). Making salient messages for Indigenous tobacco control (PhD). Cairns, QLD.: James Cook University. Retrieved from http://researchonline.jcu.edu.au/39063/1/39063-gould-2014thesis.pdf

Gould, G., McEwen, A., Watters, T., Clough, A., \& van der Zwan, R. (2013). Should anti-tobacco media messages be culturally targeted for Indigenous populations? A systematic review and narrative synthesis. Tob Control, 22, 1-11.

Hager, N. (2014). Dirty politics: how attack politics is poisoning New Zealand's political environment. Nelson, NZ: Craig Potton Publishing.

Hutcherson, G. (1995) Djalkiri Wanga. The Land is My Foundation. 50 Years of Aboriginal Art from Yirrkala, Northeast Arnhem Land. 4. Perth, WA: Berndt Museum of Anthropology.

International Working Group on Indigenous Affairs (IWGIA). (2006). The Indigenous World 2006. Copenhagen, Denmark: Danish Ministry of Foreign Affairs, NORAD, Sida and the Ministry for Foreign Affairs of Finland.

Johnston, V., \& Thomas, D. (2010). What works in Indigenous tobacco control? The perceptions of remote Indigenous community members and health staff. Health Promotion Journal of Australia, 21(1), 45-50.

Kanuha, V. (2000). "Being" Native versus "Going Native": Conducting Social Work Research as an Insider. Social Work, 45(5), 439-447.

Kariippanon, K. (Writer). (2014). Ngarali - The Tobacco Story of Arnhem Land. In K. Kariippanon (Producer). Nhulunbuy, NT: Miwatj Health Aboriginal Corporation.

Lavallee, L. (2009). Practical application of an indigenous research framework and two qualitative indigenous research methods: Sharing circles and Anishnaabe symbol-based reflection. International Journal of Qualitative Methods, 8(1), 21-40.

Macknight, C. (1976). The Voyage to Marege: Macassan Trepanger's in Northern Australia. Melbourne: Melbourne University Press.

MacLaren, D., Conigrave, K., Robertson, J., Ivers, R., Eades, S., \& Clough, A. (2010). Using breath carbon monoxide to validate self-reported tobacco smoking in remote Australian Indigenous communities. Popul Health Metr, 8(1), 1-7.

Marmot, M. (2011). Social Determinants and the health of Indigenous Australians. Aboriginal and Islander Health Worker Journal, 35(3), 21-22.

Marmot, M., \& Wilkinson, R. (2001). Psychosocial and material pathways in the relation between income and health: a response to Lynch et al. BMJ Open, 322(7296), 1233-1236.

McIntosh, I. (Ed.). (2013). Unbirri's pre-Macassan legacy or how the Yolngu became black. Canberra, ACT: The Australian National University.

Ministry of Health. (2010). Ministry of Health Report on Māori Smoking: for the Māori Affairs Select Committee. Wellington, NZ: NZ Ministry of Health.

Miwatj Health Aboriginal Corporation. (2014). Ngarali': the Tobacco Story of Arnhem Land. Nhulunbuy, NT: Miwatj Health Aboriginal Corporation.

Monin, P. (2001). This is my place: Hauraki Contested 1769-1875. Wellington, NZ: Bridget Williams Books. 
Moreton-Robinson, A. (Ed.). (2016). Critical Indigenous Studies: Engagements in first world locations. Arizona, US: The University of Arizona Press.

Morice, R. (1976). Woman dancing dreaming: Psychosocial benefits of the aboriginal outstation movement. Medical Journal of Australia, 2(25-26), 939-942.

Morphy, H. (2002). Cross-cultural categories: Yolngu science and local discourses. Paper presented at the CHAGS, Edinburgh. http://livingknowledge.anu.edu.au/html/background/discussions/ morphy_yolnguscience.pdf

Morphy, H. (2016). Extended lives in global spaces: the anthropology of Yolngu pre-burial ceremonies. Journal of the Royal Anthropological Institute, 22, 322-355.

Mulholland, E. (2008). Improving Health in East Arnhem Land. Issues, 83, 8-11.

Orange, C. (2015). The treaty of Waitangi. New Zealand: Bridget Williams Books.

Porsanger, J. (2004). An essay about Indigenous methodology. Tromso, Norway: University of Tromso.

Ratsch, A., Steadman, K. J., \& Bogossian, F. (2010). The pituri story: a review of the historical literature surrounding traditional Australian Aboriginal use of nicotine in Central Australia. $J$ Ethnobiol Ethnomed, 6, 26. doi: 10.1186/1746-4269-6-26.

Reid, J., Taylor-Moore, K., \& Varona, G. (2014). Towards a social-structural model for understanding current disparities in Māori health and well-being. Journal of Loss and Trauma, 19(6), 514-536.

Reid, P., \& Taniwha, N. (1991). Te Taonga mai Tawhiti (the gift from a distant place). Auckland: Nino Taniwha.

Rigney, L. (2001). A first perspective of Indigenous Australian participation in science: Framing Indigenous research towards Indigenous Australian intellectual sovereigny. Adelaide, SA: Flinders University.

Rigney, L. (2003). Indigenous Australian views on knowledge production and Indigenist research. Studies (AIATSIS), 1(3), 32-49.

Robertson, J. (2011). Short Ones: Tobacco stories from Arnhem Land. Cairns, QLD: James Cook University.

Rowley, C. (1970). Aboriginal Policy and Practice, 1970-71. Canberra, ACT: ANU Press.

Sbaraini, A., Carter, S., Wendell Evans, R., \& Blinkhorn, A. (2011). How to do a grounded theory study: a worked example of a study of dental practices. BMC Medical Research Methodology, 11(128), $1-10$.

Scollo, M., \& Winstanley, M. (2015). Tobacco in Australia: Facts and Issues. Melbourne, VIC: Cancer Council Victoria.

Sherwood, J., \& Edwards, T. (2006). Decolonisation: A critical step for improving Aboriginal health. Contemporary Nurse, 22(2), 178-190.

Slater, C. (2009). Exclusive: Te Reo Marama and Māori Smoking - Troughing 101. Retrieved 22 April, 2017

Smith, L. (1999). Decolonizing methodologies: research and indigenous peoples. London; New York: Zed Books; Dunedin, N.Z.: University of Otago Press.

Smith, L. (2005). On Tricky Ground: Researching the native in the age of uncertainty. In N. Denzin \& Y. Lincoln (Eds.), SAGE Handbook of Qualitative Research (6 ed.). Thousand Oaks: SAGE Publications. 
Stevenson, L., Bohanna, I., Robertson, J., \& Clough, A. (2013). Aboriginal people in remote communities in Arnhem Land (Northern Territory) restrict their smoking in some environments: Implications for developing and implementing interventions to reduce exposure to environmental tobacco smoke. Drug Alcohol Review, 32, 627-630.

Tane, M. (2014). Talking about Smoking in East Arnhem Land: Denormalisation, stigmatisation and Indigenous smoking, a grounded theory study in remote homeland communities in East Arnhem Land. Research Protocol. Menzies School of Health Research.

Tane, M. (2015). Tricky, tricky: scepticism, cynicism and smoking in remote Yolngu communities in East Arnhem Land. Paper presented at the Oceania Tobacco Control Conference, Perth, WA. https:// www.cancerwa.asn.au/resources/2015-12-07-OTCC-2015-Full-Program.pdf

Tane, M. (2016). A Killer Legacy: programs to prevent cancers amongst the Yolngu peoples must acknowledge the special relationship. Paper presented at the World Indigenous Cancer Conference, Brisbane, QLD. http://www.menzies.edu.au/icms_docs/wicc2016_ concurrentsession_6_Tane.pdf

Tatz, C. (1979). Race Politics in Australia, Aborigines, Politics and Law. Armidale, NSW: University of New England.

Thompson, L., Pearce, J., \& Barnett, J. (2007). Moralising geographies: stigma, smoking islands and responsible subjects. Royal Geographical Society, 39(4), 508-517.

Thomson, D. (1939). Notes on the smoking-pipes of north Queensland and the Northern Territory of Australia. Man(June), 81-91.

Toner, P. (2001). When the Echoes are Gone: a Yolngu Musical Anthropology (PhD). Canberra, ACT: Australia National University.

Trudgen, R. (2000). Why warriors lie down \& die : towards an understanding of why the Aboriginal people of Arnhem Land face the greatest crisis in health and education since European contact: djambatj mala. Darwin, NT: Aboriginal Resource \& Development Services Inc. (ARDS).

Williams, D. (2008). "People perish, but land is permanent": Seeking justice for the historical claims of indigenous people in New Zealand. Paper presented at the World Justice Forum, Vienna. http:// www.lexisnexis.com/documents/pdf/20080924043830_large.pdf

Yin, P. (2016). Colonisation, racism and indigenous health. Journal Population Research, 33, 83-96.

Yolngu Nations Assembly. (2011). Declaration of the Yolnuw Makarr Dhuni: Yolngu Nations Assembly (Vol. ICN 8119). Galiwin'ku, NT: Yolngu Nations Assembly.

Young, S. (1998). The Long Way Home: Repatriation for the Removal of Aboriginal Children. University of Queensland Law Journal, 20(1), 76-77. 